\title{
Premarital screening for thalassemia and sickle cell disease in Saudi Arabia
}

Nasser AbdulRahman AlHamdan, MBBS, DCH, FFCM ${ }^{1,2}$, Yagob Yousaf AlMazrou, PhD, FRCGP Fahad Mohammad AlSwaidi, MBBS, Diploma in Field Epidemiology ${ }^{1}$, and Abdul Jamil Choudhry, MSc Epidemiology, FCPS ${ }^{2}$

\begin{abstract}
Purpose: To estimate the prevalence of sickle cell disorders and beta thalassemia, with their regional distribution, in the adult population screened as part of the Saudi Premarital Screening Program. Methods: A cross-sectional, population-based study was conducted as part of the National Premarital Screening Program. It covered all the individuals who applied for a marriage license during the years 1425 and 1426 Hijra (February 2004 to January 2005). A network of 123 reception centers in the Ministry of Health facilities and 70 laboratories all over Saudi Arabia was involved in data collection. Results: Of a total of 488,315 individuals screened, $4.20 \%$ had sickle cell trait, $0.26 \%$ had sickle cell disease, 3.22\% had thalassemia trait, and $0.07 \%$ had thalassemia disease. Both the diseases were focused mainly in the eastern, western, and southwestern parts of the country. Among the 207,333 couples who were issued certificates for matching, $2.14 \%$ were declared high risk. Among the 2,375 high-risk couples contacted by telephone, $89.6 \%$ married each other, despite the known high-risk status. Conclusion: The results showed excellent access to the target population. However, the program's objective of decreasing high-risk marriages was not as successful, indicating the need for improvement of health education programs for the public, more efforts in counseling high risk couples, and changes in the strategy of timing of screening in relation to marriage. Genet Med 2007:9(6):372-377.
\end{abstract}

Key Words: Thalassemia, sickle cell disease, Saudi Arabia, screening, premarital

\section{INTRODUCTION}

Thalassemia and sickle cell disease are two well-known hemoglobinopathies. Thalassemia is caused by impaired production of either the alpha or beta hemoglobin chain and is accordingly classified as alpha or beta thalassemia. Alpha thalassemia is relatively rare, whereas beta thalassemia is quite common in certain parts of the world. Beta thalassemia clinically presents as thalassemia trait (thalassemia minor) or thalassemia major. Compared with patients with thalassemia major (HbA2 2\%, HbF 98\%, HbA Nil) who present with severe illness and require periodic blood transfusions, patients with thalassemia trait ( $\mathrm{HbA} 2>3.5 \%$, HbF Nil) are clinically well and are usually only detected through routine blood testing. However, the children of such patients could inherit the dis-

\footnotetext{
From the ${ }^{1}$ Non-Communicable Disease Program, ${ }^{2}$ Field Epidemiology Training Program, and ${ }^{3}$ Department of Preventive Medicine, Ministry of Health, Kingdom of Saudi Arabia.

Dr. Abdul Jamil Choudhry, Consultant Medical Epidemiologist, Field Epidemiology Training Program, PO Box 6344, Riyadh 11442, Kingdom of Saudi Arabia, E-mail:abduljamilch@ hotmail.com or jamil@fetp.edu.sa

Disclosure: The cost of the Saudi Premarital Screening program and the study were totally borne by different departments of the Ministry of Health, Saudi Arabia and all the authors are full-time employees of the Ministry of Health.
}

Submitted for publication December 3, 2006.

Accepted for publication March 12, 2007.

DOI: 10.1097/GIM.0b013e318065a9e8 ease if the patient's partner also has the beta thalassemia trait. Patients with sickle cell are also divided into sickle cell trait (HbS 35-38\%, HbA 62-65\%, HbA2 <3.5\%, HbF <1\%, MCV/MCH normal) and sickle cell disease (HbS $88-93 \%$, HbA Absent, $\mathrm{HbA} 2<3.5 \%$, HbF 5-10\%). ${ }^{1}$

Information about the prevalence of sickle cell disease and thalassemia in the Arab world is patchy, but studies have reported that these are relatively common genetic disorders in this part of the world. ${ }^{2}$ A number of studies conducted in Saudi Arabia demonstrated that the prevalence of these diseases varied significantly in different parts of the country, with the highest prevalence in the Eastern province of the country, followed by southwestern provinces. ${ }^{3}$ This high frequency of hemoglobinopathies is part of the general pattern of relatively common autosomal recessive hereditary diseases, which is quite understandable in a country with a consanguineous marriage rate exceeding $50 \%$, with the rate of marriage between first cousins ranging from $40 \%$ to $50 \% .4,5$

Because of the high mortality associated with thalassemia especially, and the financial, social, and psychological cost of maintenance of patients with these illnesses, prenatal and neonatal screening programs for hemoglobinopathies have been considered cost-effective in populations with a high prevalence. ${ }^{6,7}$ However, the benefit of neonatal screening programs is limited, as neonatal screening can only provide secondary or tertiary prevention among children suffering from illness. Although a prenatal 
screening program has the potential to decrease the incidence of the illness, it is not acceptable to a number of societies. In such a circumstance, a premarital screening program has a high potential to reduce the incidence of inherited diseases. ${ }^{5}$

With these considerations in mind, in 2003, the government of Saudi Arabia decided to implement a mandatory premarital screening program to decrease the incidence of the two most common hemoglobinopathies in Saudi Arabia, namely sickle cell disease and thalassemia. In this article, we present the findings of the first 2 years of the Saudi Premarital Screening Program (SPSP), which estimates the prevalence and regional distribution of sickle cell disorders and beta thalassemia in the adult population and measures the effect of the program in preventing marriage among high-risk couples.

\section{MATERIALS AND METHODS}

Saudi Arabia is a country with a population of $22,673,538$, of which $27.1 \%$ are non-Saudis. ${ }^{8}$ According to the Ministry of Justice (which is responsible for issuing marriage certificates), approximately 250,000 couples get married in the country each year. The whole country is divided into 13 administrative regions. However, the Ministry of Health has divided some of these regions into smaller regions, resulting in 20 health regions. The Ministry is responsible for providing free health care to the whole Saudi population through a network of 1824 primary health care centers and 200 hospitals (Fig. 1). ${ }^{9}$ A large number of other governmental and private organizations also participate in the provision of health care services to the population. ${ }^{9}$

Before making its final decision on the development of a mandatory national premarital screening program, the Ministry of Health held discussions in a variety of technical, religious, and social forums at national and regional levels. After the decision was made to initiate the SPSP, the necessary logistic arrangements were made to implement it. A network of 123 health care facilities (reception centers), 70 laboratories, and 20 genetic counseling clinics (to provide health education advice to high-risk couples) were assigned to provide testing and counseling services to all potential couples. All these services were to be provided to prospective couples completely free of cost, and the program was integrated into the existing health system with minimal cost impact on the Ministry of Health. All the regional coordinators of the premarital screening program, staff working in genetic counseling clinics (usually pediatricians but if not available a designated physician), and staff in charge of the regional laboratory were trained at the King Faisal Specialist Hospital and Research Center, Riyadh, which also acted as a reference laboratory for the SPSP. Comprehensive guidelines were prepared and distributed to all workers in the program throughout the country. A copy of the guidelines was added to the website of the Ministry of Health to facilitate access for workers and for rapid dissemination of updates.

Starting on the first day of the Islamic year 1425 (corresponding to February 21, 2004), the screening test was made mandatory for all couples planning to marry and applying for

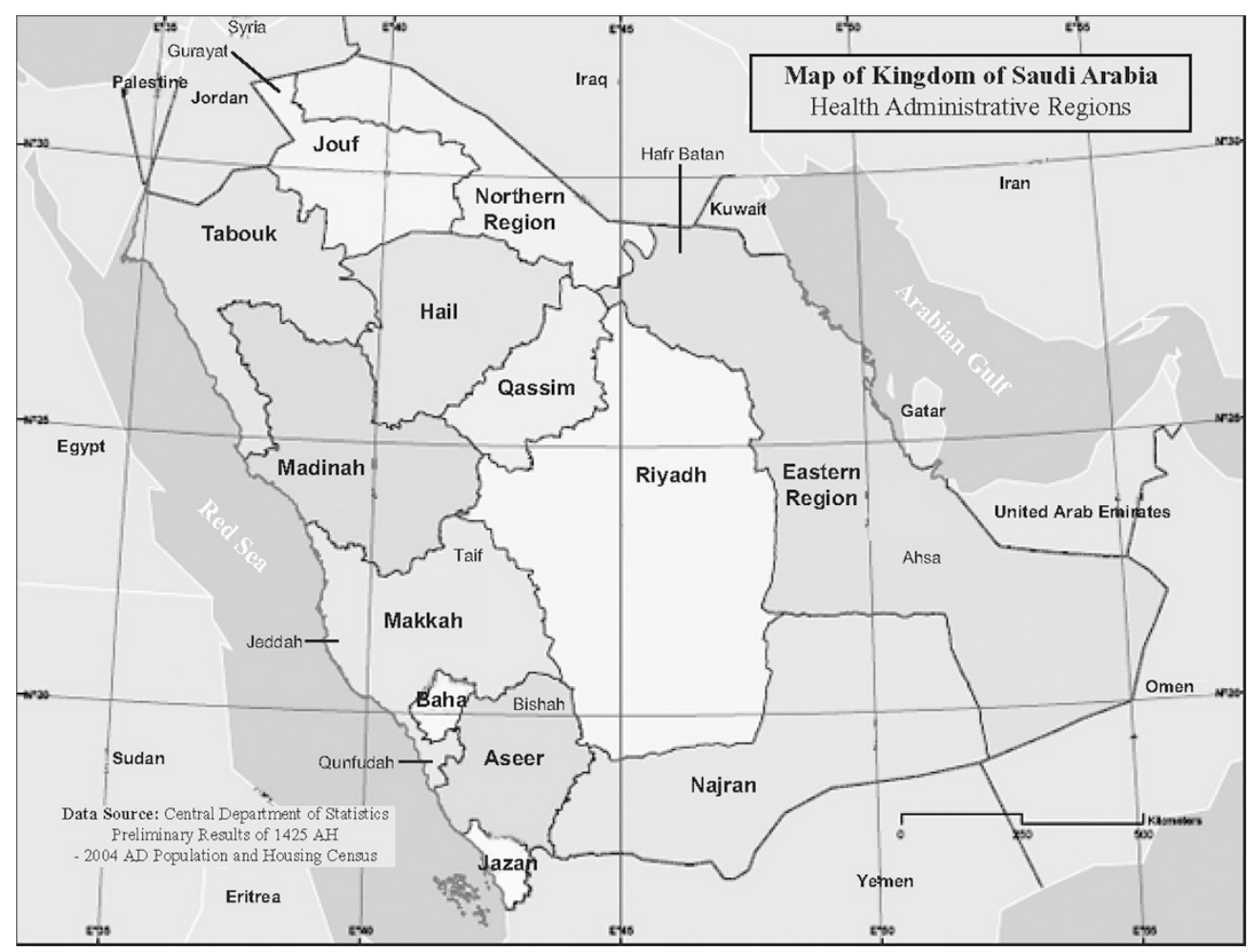

Fig. 1. Map of Saudi Arabia showing administrative and health regions (bold-face type). Additional health regions are also shown. 
a marriage license. These individuals had to contact one of the designated receptions centers, where trained staff recorded their basic demographic information and collected the blood samples in tubes containing EDTA anticoagulant before sending them to the designated laboratory. At the laboratory, the samples were subjected to a number of hematological procedures: (1) complete blood count (including hemoglobin, red cell count, hematocrit, mean corpuscular volume, red cell distribution width); (2) peripheral blood film for red blood cell morphology; (3) reticulocyte count; and (4) sickling test (addition of $2 \mathrm{~mL}$ of sodium metabisulphite to $20 \mu \mathrm{L}$ of blood; considered positive if the solution becomes turbid, whereas a clear solution is considered negative.) Main hemoglobinopathy diagnosis depended on hemoglobin electrophoresis, and results were interpreted in accordance with standard laboratory diagnostic protocols. ${ }^{1}$

All the couples found to have low risk were issued compatibility certificates. However, if both members of the potential couple were found positive for sickle cell trait/disease and/or thalassemia trait/disease, they were declared high risk. These couples were not issued a marriage certificate and were referred to a regional genetic counseling clinic. Both prospective partners (or male partner along with the guardian of the female partner) visited these centers together by appointment. During the meeting, the counselor explained the situation to both the partners and issued them "certificates of incompatibility" after obtaining their signatures and providing them with health education brochures. Couples had the right to marry regardless of the screening test results. All the high-risk couples are being followed up to evaluate the success of the program, results of which will be presented later.

Availability of lab reagents and equipment in all assigned laboratories was treated as a priority, as was having qualified personnel to run the program. Staff received continuous training and supervision, and special training sessions were designed to be held annually (e.g., genetic counseling session for the genetic counseling physicians working in the clinics, review meeting for all coordinators in the regions, and sessions for reporting and data entry).

All the laboratory data were collected at regional levels and transmitted to the SPSP office in the Directorate General of Noncommunicable Disease in Riyadh on a regular basis. However, no personal identification information was routinely transmitted along with these data. After obtaining permission from the concerned authorities, data were procured from the program office, compiled, and analyzed using Microsoft Excel software. Standard errors of proportion and 95\% confidence intervals were calculated by using the standard formula. ${ }^{10}$

\section{RESULTS}

A total of 488,315 individuals were screened under the program during the 2-year reporting period (i.e., from Muharram 1, 1425 Hijri to Dhul Hajja 30, 1426 Hijri, which corresponds to February 21, 2004 through January 30, 2006). During the year $1425 \mathrm{Hijri}, 241,825$ individuals were screened, and 246,490 individuals were screened during year $1426 \mathrm{Hijri}$. The highest proportion of screened individuals was from the Riyadh region (21.46\%), followed by Aseer (9.66\%), and Jeddah $(8.86 \%)$, which in general follows the proportion of these regions in the national population. The highest number of screened individuals was registered during the month of Jumadi II (sixth Hijri month), corresponding to July 2004 and 2005, whereas the lowest number was registered during Ramadan (ninth Hijri month), corresponding to October 2004 and 2005 (Fig. 2).

The total number of individuals identified with sickle cell trait was 20,530 (4.20\%) and with sickle cell disease was 1,251 $(0.26 \%)$. Al-Ahsa region presented the highest rates of sickling (sickle cell trait 16.89\% and sickle cell disease 1.20\%), followed by Qunfudah, Eastern region, and Jazan. Other regions showed much lower prevalence rates. (Table 1).

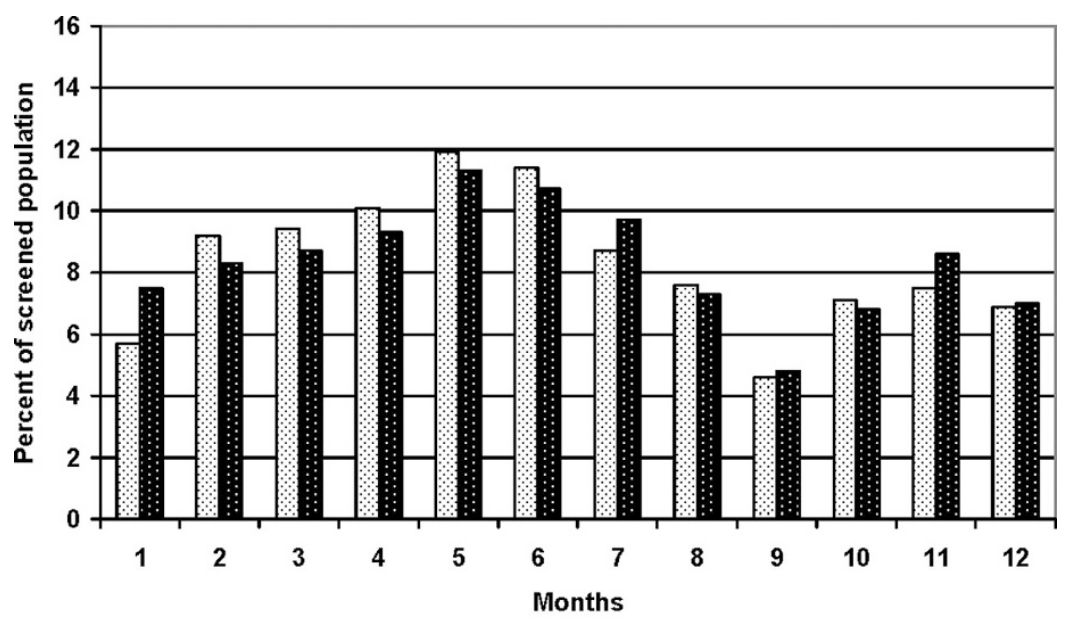

O1425 Hijri B 1426 Hijri

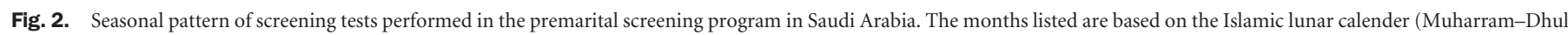
Hajja), not the Gregorian calender. 
Table 1

Regional distribution of sickle cell disorder and thalassemia detected by the Premarital Screening Program of Saudi Arabia

\begin{tabular}{|c|c|c|c|c|c|c|c|c|c|}
\hline \multirow[b]{2}{*}{ Region } & \multirow[b]{2}{*}{ Tests performed } & \multicolumn{4}{|c|}{ SCD } & \multicolumn{4}{|c|}{ Thalassemia } \\
\hline & & Trait & $95 \% \mathrm{CI}$ & Disease & $95 \% \mathrm{CI}$ & Trait & $95 \% \mathrm{CI}$ & Disease & $95 \%$ CI \\
\hline Riyadh & 104,802 & 2.08 & $2.00-2.17$ & 0.15 & $0.12-0.17$ & 2.01 & $1.92-2.09$ & 0.15 & $0.12-0.17$ \\
\hline Makkah & 26,945 & 3.12 & $2.91-3.32$ & 0.10 & $0.06-0.14$ & 2.72 & $2.52-2.91$ & 0.01 & $0.00-0.03$ \\
\hline Jeddah & 43,279 & 3.46 & $3.29-3.63$ & 0.04 & $0.02-0.06$ & 1.23 & $1.13-1.33$ & 0.00 & $0.00-0.00$ \\
\hline Madinah & 31,183 & 2.06 & $1.90-2.22$ & 0.13 & $0.09-0.16$ & 0.41 & $0.34-0.48$ & 0.07 & $0.04-0.10$ \\
\hline Qassim & 27,333 & 0.21 & $0.16-0.27$ & 0.01 & $0.00-0.03$ & 0.11 & $0.07-0.14$ & 0.02 & $0.00-0.03$ \\
\hline Taif & 27,187 & 1.07 & $0.94-1.19$ & 0.01 & $0.00-0.02$ & 0.43 & $0.35-0.51$ & 0.00 & $0.00-0.01$ \\
\hline Hail & 13,892 & 0.14 & $0.08-0.21$ & 0.06 & $0.02-0.10$ & 0.02 & $0.00-0.05$ & 0.00 & $0.00-0.00$ \\
\hline Baha & 14,442 & 3.34 & $3.04-3.63$ & 0.02 & $0.00-0.04$ & 0.76 & $0.62-0.90$ & 0.01 & -0.01 to 0.02 \\
\hline Assir & 47,177 & 2.89 & $2.74-3.04$ & 0.08 & $0.06-0.11$ & 0.30 & $0.25-0.35$ & 0.01 & $0.00-0.01$ \\
\hline Eastern region & 42,095 & 10.74 & $10.44-11.03$ & 0.87 & $0.78-0.96$ & 19.50 & $19.12-19.87$ & 0.06 & $0.04-0.09$ \\
\hline Ahsa & 27,238 & 16.89 & $16.45-17.34$ & 1.20 & $1.07-1.33$ & 3.10 & $2.89-3.30$ & 0.08 & $0.05-0.11$ \\
\hline Qunfudah & 5,166 & 12.66 & $11.75-13.57$ & 0.31 & $0.16-0.46$ & 15.85 & $14.86-16.85$ & 0.00 & $0.00-0.00$ \\
\hline Hafr Batin & 7,989 & 0.39 & $0.25-0.52$ & 0.00 & $0.00-0.00$ & 0.00 & $0.00-0.00$ & 0.01 & $-0.01-0.04$ \\
\hline Jazan & 23,012 & 11.73 & $11.31-12.14$ & 0.90 & $0.77-1.02$ & 7.81 & $7.46-8.16$ & 0.39 & $0.31-0.47$ \\
\hline Najran & 9,260 & 1.57 & $1.31-1.82$ & 0.02 & -0.01 to 0.05 & 0.02 & $-0.01-0.05$ & 0.00 & $0.00-0.00$ \\
\hline Bishah & 7,902 & 1.99 & $1.68-2.29$ & 0.01 & -0.01 to 0.04 & 0.04 & $0.00-0.08$ & 0.01 & $-0.01-0.04$ \\
\hline Tabuk & 13,798 & 2.24 & $1.99-2.49$ & 0.24 & $0.16-0.32$ & 0.30 & $0.21-0.40$ & 0.01 & -0.01 to 0.03 \\
\hline Jouf & 6,008 & 0.18 & $0.07-0.29$ & 0.05 & -0.01 to 0.11 & 0.07 & $0.00-0.13$ & 0.00 & $0.00-0.00$ \\
\hline Northern region & 5,891 & 0.24 & $0.11-0.36$ & 0.05 & -0.01 to 0.11 & 1.85 & $1.51-2.19$ & 0.27 & $0.14-0.40$ \\
\hline Gurayat & 3,716 & 0.38 & $0.18-0.57$ & 0.00 & $0.00-0.00$ & 0.43 & $0.22-0.64$ & 0.00 & $0.00-0.00$ \\
\hline Total & 488,315 & 4.20 & $4.15-4.26$ & 0.26 & $0.24-0.27$ & 3.22 & $3.17-3.27$ & 0.07 & $0.06-0.08$ \\
\hline
\end{tabular}

SCD, sickle cell disease.

Regarding beta thalassemia, 15,740 (3.22\%) of the individuals screened were found positive for thalassemia trait, and 348 $(0.07 \%)$ were found positive for thalassemia disease. Thalassemia trait was highest in the Eastern region (19.50\%), followed by Qunfudah (15.85\%), Jazan (7.81\%), and Ahsa (3.10\%). Thalassemia disease was highest in Jazan $(0.39 \%)$, followed by the Northern region $(0.27 \%)$, Riyadh $(0.15 \%)$, and Ahsa $(0.08 \%)$ (Table 1$)$.

Among the 207,333 couples who were issued certificates for compatibility based on screening tests, 4,444 (2.14\%; $95 \%$ CI $2.08-2.21 \%$ ) were declared high risk. The majority of high-risk certificates (mismatched results) were issued from the Eastern province (43.5\%), followed by Al-Ahsa (22.1\%), Jazan (16.2\%), and Makkah (5\%).

Among the 2441 couples who were tested during the year 1425 Hijri (corresponding to February 21, 2004 to February 9, 2005) and declared high risk, 1213 couples were contacted by telephone, and it was found that 1101 (90.8\%) of them had married each other, despite the known incompatibility status. For the year 1426 Hijri (corresponding to February 10, 2005 to January 30, 2006), among the 2003 couples that were declared high risk, 1162 were contacted by telephone, and 1027 (88.4\%) were found to have married each other.

\section{DISCUSSION}

As expected, results from the screening program show that, among adults looking to marry, the overall prevalence of sickle cell trait/disease and thalassemia was quite high and resulted in incompatibility in more than $2 \%$ of the couples. These figures are much higher than the figures reported from western countries and may be considered nearer to other studies conducted in the Gulf Cooperation Council (GCC) countries, which have also shown relatively high prevalence of both of these hemoglobinopathies. A study in the United Arab Emirates demonstrated a $0.07 \%$ prevalence of sickle cell disease and $1.5 \%$ prevalence of sickle cell trait among neonates, and an Omani study showed a $0.2 \%$ prevalence of sickle cell disease, a $6 \%$ prevalence of sickle cell trait, and a $2 \%$ prevalence of beta thalassemia among children younger than 5 years of age. ${ }^{11,12}$ These estimates are not directly comparable to our study population because they report figures among neonates or young children-except for a study that reported figures for the antenatal population in the United Kingdom. ${ }^{13}$ Prevalence of hemoglobinopathies in our study population is not only dependent on the incidence of the disease at the time of conception, but is 
also a product of the incidence of disease and the survival pattern of affected individuals up to the age of marriage. Because this survival pattern is dependent on the severity of illness and health care service availability and its utilization, this study is likely to present a lower prevalence of sickle cell disease and thalassemia major compared with studies measuring sickle cell trait or thalassemia minor in children.

Regional comparison has shown that the hemoglobinopathies are concentrated in two geographically contiguous blocks, one in the eastern part of the country (the Eastern region and Ahsa) and the other in the southwestern part of the country (Jazan and Qunfudah), which conforms to the pattern of these diseases previously reported. ${ }^{3}$ The Saudi community is basically a tribal society with a high proportion of consanguineous marriages, which means the recessive genes have been able to survive, concentrate, and exhibit disease in these populations over the centuries. This phenomenon has been described as the major reason for higher prevalence of autosomal recessive disorders in similar populations. ${ }^{14}$ However, there is some variation in the pattern of thalassemia minor and major among the regions. The thalassemia trait is more prevalent in the regions previously mentioned, but the prevalence of thalassemia disease is also high in regions like Makkah (a western region) and the Northern region, which may reflect a different survival pattern and suggests further exploration into the matter.

As seen in a subset of the high-risk couples, almost $90 \%$ married each other despite being aware of the risk, although a downward trend was observed for the year $1426 \mathrm{Hijri}$ (corresponding to February 10, 2005 to January 30, 2006) compared with 1425 Hijri (corresponding to February 21, 2004 to February 9,2005$)$. This shows that the program was successful in screening the vast majority of eligible individuals, identifying the couples at risk of having children with sickle cell trait/disease or thalassemia, and providing them with health education. However, it was not successful in achieving the main goal of decreasing the incidence of these diseases in future generations by eliminating or significantly decreasing the number of highrisk marriages. The option of prenatal diagnosis for these diseases is practically unavailable in the current health system. When it is available, the option of abortion is either unavailable or unacceptable to families because of social and/or religious reasons. Considering the fertility pattern of the population and health care system available, practically all high-risk marriages are likely to produce children at high risk of hemoglobinopathies.

A way of improving this scenario is to offer the screening test to young adults at an earlier stage, such as immediately after high school, so that they can discuss the issue in the early phase of the marriage proposal. To strengthen the program, a regular follow-up of the high-risk couples has already been included in the system with the cooperation of the Justice Department (which is responsible for registering all marriages and issuing marriage certificates for all the marriages in the country). Integration of the premarital screening program with the national neonatal screening program, started this year, will hopefully be able to address the problem in the longer run. Furthermore, a case-controlled study is currently being con- ducted to explore the reasons why, despite counseling, highrisk couples go on to marry.

In developing countries, major determinants of consanguineous marriages are sociocultural factors, which are resistant to change. ${ }^{15}$ A number of other reasons could be responsible for this failure, such as screening at a late stage in the marriage process (the screening test is usually performed after the formal engagement), difficulty in finding an alternative socially suitable match, commitment of the couple to each other, or failure of health staff in providing adequate information to the couples to change their decision. There could be another dimension of possible psychosocial stigma attached to declaring the incompatibility to the community. However, it is less likely to be a major issue considering the current general level of information in the community leading to a fatalistic attitude of society toward the occurrence of these illnesses. In the future, as more adults know about their trait/disease status, coupled with poor understanding of the disease process, otherwise suitable prospects may tend to avoid marriage with these individuals. This prospective scenario highlights the need for a mass education campaign to be comprehensive and precise while focused on the alleviation of scientifically incorrect fears.

A seasonal pattern in the request for screening tests has been exhibited; they peak in the middle of summer vacation. This means that the centers and labs involved in the premarital screening program must have adequate staff and lab facilities during this period to cope with the expected workload.

Undertaking this type of screening program takes a heavy toll on the human and financial resources of the health care departments, especially the reception centers and medical laboratories involved. However, implementation and operation of the program has been quite smooth, and there is no indication of any major system failure. Screening programs have been notorious for being too expensive, even in rich countries, so the long-term sustainability of the program depends on the financial and cost-effectiveness analysis of the program. ${ }^{16}$ The program is provided free of cost to the target couples, and to control the cost of the program, it is completely integrated into the existing health care system by using the existing laboratories and training the existing staff through existing training facilities, and the program was developed by existing staff in the Ministry of Health. The only real additional cost of the program is the cost of test kits and the development of a small central coordinating unit and health education material. One way of improving the cost-effectiveness of the program even further may be to expand it to include other hereditary diseases and chronic infectious diseases like HBV, HCV, and HIV, subject to feasibility and ethical issues involved. A consultative process to explore this option is in progress.

The results showed excellent access to the target population, with a high prevalence of carriers and individuals with disease in the eastern and southwestern regions of the country. However, the objective of the program-to decrease high-risk marriages-was not as successful, although it did improve over time. To improve this outcome, we recommend intensification 
of the counseling mechanism for the high-risk couples, strengthening of the health education program for the general population, and changes in the timing of screening in relation to marriage (e.g., at the end of high school).

\section{ACKNOWLEDGMENTS}

We acknowledge the contribution of Mr. Muhammad Ibrahim AlOmer, Director General of Laboratories and Blood Banks, Ministry of Health, without whose active support the premarital screening program could not be a success.

\section{References}

1. Wild BJ, Bain BJ. Investigation of abnormal hemoglobins and thalassemia. In: Lewis SM, Bain BJ, Bates I, editors. Dacie \& Lewis practical hematology, 9th edition. London: Churchill Livingstone, 2001:231-268.

2. El-Hazmi AF, Warsy AS. Hemoglobinopathies in Arab countries. In: Teebi AS, Farag TI, editors. Genetic disorders among Arab populations. Oxford monographs on medical genetics, No. 30. New York: Oxford University Press, 1999:83-110.

3. El-Hazmi MAF, Warsy AS. Appraisal of sickle cell and thalassemia genes in Saudi Arabia. East Mediterr Health J 1999;5:1147-1153.

4. Rashad H, Osman M, Roudi-Fahimi F. Marriage in the Arab world. Washington: Population Reference Bureau, 2005.

5. Meyer BF. Strategies for the prevention of hereditary diseases in a highly consanguineous population. Ann Hum Biol 2005;32:174-179.

6. Caughey AB. Cost-effectiveness analysis of prenatal diagnosis: methodological issues and concerns. Gynecol Obstet Invest 2005;60:11-18.
7. Almeida AM, Henthorn JS, Davies SC. Neonatal screening for haemoglobinopathies: the results of a 10-year programme in an English Health Region. Br J Haematol 2001;112:32-35.

8. Ministry of Economic and Planning, Kingdom of Saudi Arabia. Preliminary results of the census operation $1425 \mathrm{H}-2005$. Available at http://www.planning.gov.sa/ statistic/cdsonnet/demographicmap/escripts/prepop.asp. Accessed September 6, 2006.

9. Ministry of Health, Kingdom of Saudi Arabia. Statistical Year Book 1424 Hijri. Riyadh: Ministry of Health, 2006:105.

10. Kirkwood BR, Sterne JAC. Essential medical statistics, 2nd edition. Massachusetts: Blackwell Science, 2003:143-144.

11. Al Hosani H, Salah M, Osman HM, Farag HM, Anvery SM. Incidence of haemoglobinopathies detected through neonatal screening in the United Arab Emirates. East Mediterr Health J 2005;11:300-307.

12. Al-Riyami A, Ebrahim GJ. Genetic blood disorders survey in the sultanate of Oman J Trop Pediatr 2003;49 Suppl 1:i1-20.

13. Kadkhodaei Elyaderani M, Cinkotai KI, Hyde K, Waters HM, Howarth J, Goldstone $\mathrm{S}$, et al. Ethnicity study and non-selective screening for haemoglobinopathies in the antenatal population of central Manchester. Clin Lab Haematol 1998;20: 207-211.

14. Madi SA, Al-Naggar RL, Al-Awadi SA, Bastaki LA. Profile of major congenital malformations in neonates in Al-Jahra region of Kuwait. East Mediterr Health J 2005; 11:700-706.

15. Hussain R. Community perceptions of reasons for preference for consanguineous marriages in Pakistan. J Biosoc Sci 1999;31:449-461.

16. Autti-Ramo I, Makela M, Sintonen H, Koskinen H, Laajalahti L, et al. Expanding screening for rare metabolic disease in the newborn: an analysis of costs, effect and ethical consequences for decision-making in Finland. Acta Paediatr 2005;94:11261136. 